Theories \& Applications, the International Edition

Printed Version: (ISSN 2090-5262)

Online Version: (ISSN 2090-5270)

July 2013, Volume 3, No. 2 Pages (101 - 108)

\title{
Education and Training Program for Some of the Floor Games Skills and Its Impact on the Effectiveness of Skilled Performance among Judo Beginners
}

\author{
Mohamed Hamed Shadad*, Abdulhalim Mohamed Abdulhalim**, Khaled Farid Ezzat***
}

\begin{abstract}
The researchers conduct this study to take advantage of the skills of floor game which gives three possibilities to win the game by designing an educational and training program for some of the floor game skills among Judo beginners and identifying the impact of the educational, training program on the effectiveness of skilled performance among Judo beginners. The researchers used the experimental method because of its suitability for the nature of the study and its objectives. The researchers used the experimental design for two groups, one experimental group and the other is control group. The sample was chosen by the intentional way from Fishing Club (El Sied) under (17 years old) and it contains (16 beginners) and they were divided into two groups, one experimental and the other is control (8 beginners) in each group by the intentional way. In collecting the data of the study the researchers used a recording form for games results, which was prepared by the researchers and a form of experts' poll to identify the suitable skills of floor game for the research sample and to determine the main aspects of the proposed educational, training program.
\end{abstract}

\section{Introduction and Research Problem}

$\mathrm{J}$ udo is an art and its goal is to drop the opponent down on his back strongly and quickly or pinning the opponent for $(25 \mathrm{sec})$ or make him surrender due to a strangling skill or breaking (16:4)

Through the above definition it is clear that Judo is divided techniques of play from the top including throwing using hands, waste, and legs skills and the skills of side scarifying including the techniques of pinning and the techniques of strangling and breaking.

The researchers believe that both playing from the top and floor games complete each other to defeat the opponent with the maximum performance and less effort as possible.

The research problem emerging through the researchers' observation during practicing Judo as players and then as coaches is that training to play from the top is the skill that get all the

\footnotetext{
* Professor in sports training department-faculty of physical education, Helwan University, Egypt.

** Assistant professor in fighting and water sports-faculty of physical education, El Monofya University, Egypt.

*** Teacher in the department of teaching and methods-faculty of physical education, El Mansura University, Egypt.
}

attention and the floor games is neglected while the skill of playing from top is completing the skill of floor games as the contestants can switch from playing from top to floor games when one of the contestants get some results through one of the throw techniques and turn without stopping and continue to attack through using the floor games techniques.

The researchers also noticed that most of the beginners after performing playing from above skill do not complete their attack directly using the techniques of floor games due to that coaches neglect the floor games skills which gives the opponent an opportunity to take the appropriate defense position for floor games which is to lie on the abdomen covering the neck with hands which leads the attacking player to start over again in attacking the opponent through the floor games techniques, which make it hard on the attacking player to apply the skills of floor games and then the referee calls for (Mattei) which means stop playing to continue playing again with the playing from the top skill while the floor games is given three possibilities to win the game is wining through pining for 25 seconds, breaking, or strangling. As for playing from top, it gives 
one possibilities to win the game and it is to throw from the top.

Hence, the researchers came up with designing a training, educational program for some floor games skills and to submit to the study of the impact of a proposed training, educational program on the effectiveness among Judo beginners.

\section{Research Objectives}

1. Designing a training, educational program for some of the floor games skills among Judo beginners.

2. Identifying the impact of the training, educational program on the effectiveness of the performance among Judo beginners.

3. There are statistically significant differences between the pre and post measurements of the experimental group in the effectiveness of skill performance for the post measurement.

4. There are statistically significant differences between the two post measurements of the experimental and control groups in the effectiveness of skill performance for the experimental group post measurement.

\section{Research Terms}

\section{Floor Games Techniques (Katamy Waza)}

It is all the skills of the floor games including pinning (osae waza), strangling (shime waza), and breaking (kansetsu waza). (Procedural definition)

\section{The Effectiveness of Skill Performance}

The beginner ability to score the largest possible number of yuko, waza, and ippon during the games (procedural definition)

\section{Research Hypothesis}

\section{Research Procedurals}

\section{Research Method}

The researchers chose the experimental method for its suitability to the study nature and objectives. The researchers used the experimental design for two groups one is experimental and the other is controlled.

\section{Research Sample}

The researchers chose the sample in the intentional way fro the beginners of el sied club (under 17) it consists of (16) beginners, they were divided into two groups one experimental and the other is control (8) beginners in each group randomly.

Table (1)

The torsion coefficient of the research sample in the variable of age, tall, and weight $N=16$

\begin{tabular}{|c|c|c|c|c|c|}
\hline Variables & Meas. unit & $\mathrm{A}$ & $\mathrm{R} 2$ & $\mathrm{~S}+$ & $\mathrm{T}$ \\
\hline age & year & 16.85 & 16.90 & 0.39 & $0.38-$ \\
\hline tall & $\mathrm{cm}$ & 168.23 & 167.14 & 4.55 & 0.72 \\
\hline weight & k.gm & 80.63 & 79.45 & 18.75 & 0.19 \\
\hline
\end{tabular}

( $A=$ Arithmetic mean, $s+=$ standard deviation, $r 2=$ average, $T=$ the value of torsion coefficient $)$

Table (1) shows that the torsion coefficient in the variables (age, tall, and weight) average between $(0.38-60.19)$ meaning it is between $(+3)$
That is referring to the equation of the sample individual data in the chosen variables. 
Table (2)

The significant differences between (experimental/control) groups in the physical variables for Judo beginners under $(17$ years $)(N 1=N 2=8)$

\begin{tabular}{|c|c|c|c|c|c|c|}
\hline \multirow{2}{*}{ test } & \multirow{2}{*}{$\begin{array}{c}\text { Meas. } \\
\text { unit }\end{array}$} & Experimental & \multicolumn{2}{|c|}{ Control } & \multirow{2}{*}{$\mathrm{T}$} \\
\cline { 3 - 8 } & Min & 5.7 & 0.65 & 5.45 & 0.66 & 0.67 \\
\hline Running 1000 m. & no & 13 & 1.62 & 12 & 1.67 & 0.26 \\
\hline model of the Leaning lie & degree & 18.7 & 3.4 & 18.10 & 2.90 & 0.37 \\
\hline Leaping on signs & $\mathrm{Cm}$ & 17.50 & 3.92 & 16.90 & 30.05 & 0.36 \\
\hline The horizontal distance of the bridge & $\mathrm{No}$ & 16 & 2.20 & 15 & 1.98 & 0.14 \\
\hline Sit lie down, knees bent & No & $\mathrm{A}$ & $\mathrm{s}+$ & \\
\hline Leaping in the place (15 sec) & No & 10 & 0.64 & 11 & 0.62 & 0.29 \\
\hline Lifting the shoulder of lie & $\mathrm{Cm}$ & 8.5 & 1.60 & 7.9 & 1.30 & 0.12 \\
\hline Leaping on the circuit & Sec & 7.9 & 1.8 & 7.02 & 0.98 & 0.39 \\
\hline
\end{tabular}

(T) Value at (0.05) level $=1.717$

Table (2) shows that there are no statistical significant differences at the level (0.05) between the two groups (experimental and control) in the physical variables among Judo beginners under (17 years).

\section{Data Collecting Tools}

- A form for recording the games' results prepared by the researchers (annex 1).

- A form for experts' poll to identify the skills of floor games which are suitable for research sample (annex 2) and to determine the basic aspects of the proposed training, educational program (annex 3).

\section{Pre-Measurement}

The researchers conduct the pre-measurement to measure the effectiveness of the skilful performance through holding three experimental games (floor games) between the experimental and control group, and then the researchers record the results of the three games. Table (3) shows the equivalent between the two groups in the effectiveness of skilful performance.

Table (3)

The pre-measurement between the two groups (experimental/control) in the effectiveness of skilful performance

\begin{tabular}{|c|c|c|c|}
\hline \multirow{2}{*}{ Skilled variables } & \multicolumn{2}{|c|}{ Pre-measurement } & \multirow{2}{*}{ Ka2 value } \\
\cline { 2 - 3 } & Experimental & Control & \\
\hline Yuko from pinning skills & 5 & 4 & 0.39 \\
\hline Waza from pinning skills & 7 & 8 & 0.15 \\
\hline Ippon from pinning skills & 6 & 7 & 0.21 \\
\hline ippon from strangling skills & 4 & 4 & 0.65 \\
\hline Ippon from breaking skills & 4 & 3 & 0.15 \\
\hline applying pinning skills without effectiveness & 9 & 10 & 0.14 \\
\hline applying strangling skills without effectiveness & 5 & 6 & 0.23 \\
\hline applying breaking skills without effectiveness & 3 & 4 & 0.14 \\
\hline Warnings & 6 & 5 & 0.06 \\
\hline Win & 10 & 14 & 0.67 \\
\hline Defeat & 14 & 10 & 0.67 \\
\hline
\end{tabular}

The value of $\mathrm{ka} 2$ at the level $(0.05)=3.84$

Table (3) shows there are no statistical significant differences at the level (0.05) in the pre-measurement of the two groups in the effectiveness of skilful performance.

\section{The Proposed Training, Educational Program}

The basics of developing the proposed training, educational program
1. Identifying the basic aspects of the proposed training, educational program.

2. Determining the duration of the basic aspects of the proposed training, educational program.

3. Determining the skills of floor games used in the proposed training, educational program as the skills have been submitted to the experts and (10) skills have been chosen as they are suitable skills for the age stage and for the required 
purpose, and they are 4 pinning skills, 3 strangling skills, and 3 breaking skills.

4. Determining the proper method of teaching the chosen skills of floor games, the experts had agreed on using the following methods in the proposed educational program (partial methodtotal method).

5. Determining the intensity, size, and rest of the floor games skills used in the proposed training program as the load intensity ranged between $(60 \%-90 \%)$ for experimental group in the chosen skills of floor games in question ,the size ranged from (5-10) groups, and the rest( from 1 to 3 minutes)

6. Determining the used method of training in the proposed training program, the experts had agreed on using the duration training methods (low/high intensity).

\section{The Proposed Educational Program}

The researchers divided the educational program into three stages, the duration of each stage is a week, 3 training unit per week. The unit duration is (60 minutes).

- First stage: the experimental group is trained for the chosen pinning skills which are as follows:

(Kesa gatame- kuzure kesa gatame- yuko shiho gatame- kami shiho gatame)

- Second stage: the experimental group is trained for the chosen strangling skills which are as follows:

(Hadaka jime- sankaku jime- Kata ha jime)

- Third stage: the experimental group is trained for the chosen breaking skills which are as follows:

(audi juji gatame- audi grami- Hiza gatame) annex (4)

\section{The Proposed Training Program}

The researchers divided the training program into three stages, the duration of each stage is a week, 3 training unit per week. The unit duration is (90 minutes).

- First stage: the experimental group is trained for the chosen pinning skills which are as follows:

(Kesa gatame- kuzure kesa gatame- yuko shiho gatame- kami shiho gatame)

- Second stage: the experimental group is trained for the chosen strangling skills which are as follows:

(Hadaka jime- sankaku jime- Kata ha jime)

- Third stage: the experimental group is trained for the chosen breaking skills which are as follows:

(audi juji gatame- audi grami- Hiza gatame) annex (5).

\section{Applying the Proposed Training, Educational Program}

The proposed educational program was applied on Saturday 23/6/2012 till Wednesday 11/7/2012, (9) educational units. The proposed training program was applied on Saturday 14/7/2012 till Wednesday 22/8/2012, (18) training units.

\section{Post-Measurement}

The researchers conduct the post-measurement to measure the effectiveness of the skilful performance through holding three experimental games (floor games) between the experimental and control group, and then the researchers record the results of the three games through the form of recording data.

8-results presentation: 
Table (4)

Significance differences between (pre/post) measurements of the experimental group in the effectiveness of skilled performance

\begin{tabular}{|c|c|c|c|c|}
\hline Skill variables & Pre-meas. & Post-meas. & Ka2 value & Pre/postMeas. \\
\hline Yuko from pinning skills & 5 & 11 & 0.23 & \\
\hline Waza from pinning skills & 7 & 9 & 0.16 & \\
\hline Ippon from pinning skills & 6 & 8 & 0.17 & \\
\hline Ippon from strangling skills & 4 & 7 & 3.95 & post \\
\hline Ippon from breaking skills & 4 & 6 & 4.74 & post \\
\hline applying pinning skills without effectiveness & 9 & 14 & 0.5 & \\
\hline applying strangling skills without effectiveness & 5 & 12 & 0.26 & \\
\hline applying breaking skills without effectiveness & 3 & 8 & 0.06 & \\
\hline Warnings & 6 & 10 & 3.70 & post \\
\hline win & 10 & 21 & 3.90 & post \\
\hline Defeat & 14 & 3 & 7.12 & pre \\
\hline
\end{tabular}

Form (4)

Significance differences between (pre/post) measurements of the experimental group in the effectiveness of skilled performance

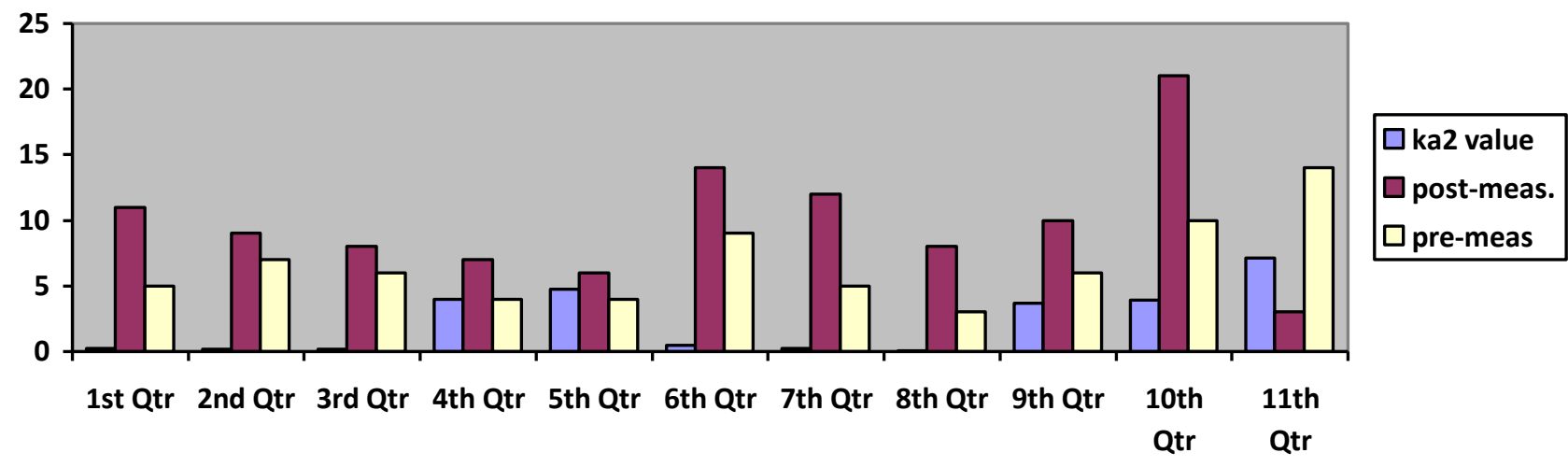

Table (5)

Significance differences between (pre/post) measurements of the control group in the effectiveness of skilled performance

\begin{tabular}{|c|c|c|c|c|}
\hline Variable skills & $\begin{array}{c}\text { Pre } \\
\text { Meas. }\end{array}$ & $\begin{array}{l}\text { Post } \\
\text { Meas. }\end{array}$ & $\mathrm{Ka} 2$ value & $\begin{array}{c}\text { Pre/post } \\
\text { Meas. }\end{array}$ \\
\hline Yuko from pinning skills & 4 & 5 & 0.47 & \\
\hline Waza from pinning skills & 8 & 7 & 0.36 & \\
\hline Ippon from pinning skills & 7 & 1 & 0.05 & \\
\hline ippon from strangling skills & 4 & 1 & 2.23 & Pre \\
\hline Ippon from breaking skills & 3 & 1 & 0.14 & \\
\hline applying pinning skills without effectiveness & 10 & 6 & 0.4 & \\
\hline applying strangling skills without effectiveness & 6 & 5 & 0.5 & \\
\hline applying breaking skills without effectiveness & 4 & 5 & 0.05 & \\
\hline Warnings & 5 & 3 & 0.2 & \\
\hline Win & 14 & 3 & 7.12 & Pre \\
\hline Defeat & 10 & 21 & 3.90 & post \\
\hline
\end{tabular}


Form (5)

Significance differences between (pre/post) measurements of the control group in the effectiveness of skilled performance

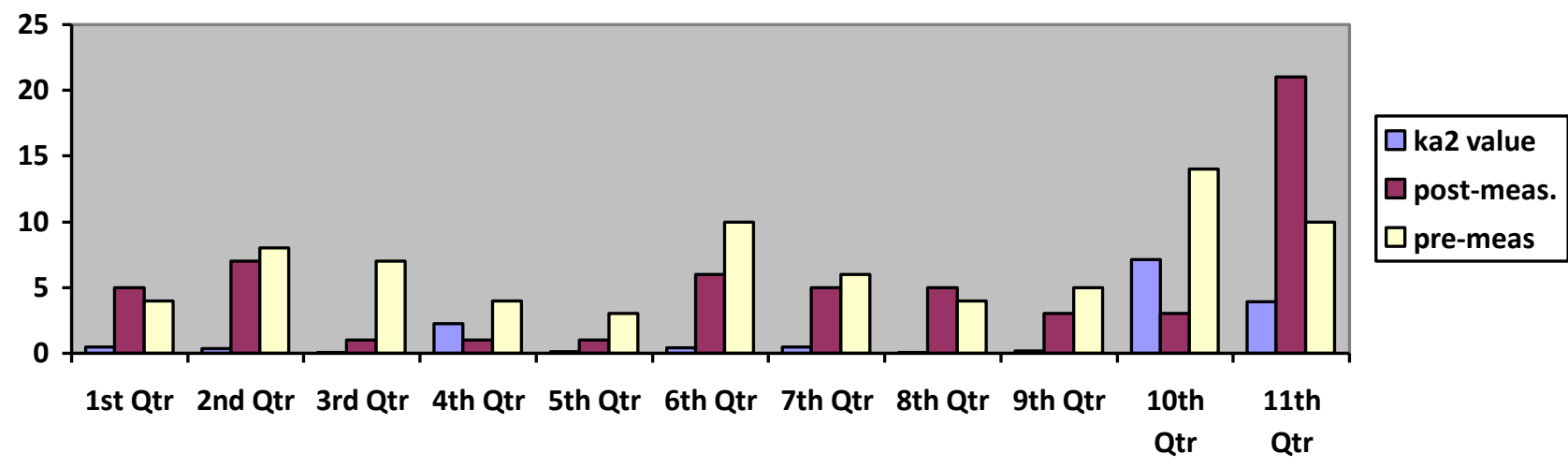

Table (6)

Significance differences between the two post-measurements of experimental/control groups in the effectiveness of the skilled performance

\begin{tabular}{|c|c|c|c|c|}
\hline Variable skills & Exp erimental & control & K2 value & Group \\
\hline Yuko from pinning skills & 11 & 5 & 0.23 & \\
\hline Waza from pinning skills & 9 & 7 & 0.16 & \\
\hline Ippon from pinning skills & 8 & 1 & 4.27 & experimental \\
\hline ippon from strangling skills & 7 & 1 & 6.12 & experimental \\
\hline Ippon from breaking skills & 6 & 1 & 5.28 & experimental \\
\hline applying pinning skills without effectiveness & 14 & 6 & 0.5 & \\
\hline applying strangling skills without effectiveness & 12 & 5 & 0.26 & \\
\hline applying breaking skills without effectiveness & 8 & 5 & 0.06 & \\
\hline Warnings & 10 & 3 & 3.70 & experimental \\
\hline win & 21 & 3 & 3.90 & experimental \\
\hline Defeat & 3 & 21 & 7.12 & experimental \\
\hline
\end{tabular}

Form (6)

Significance differences between the two post-measurements of experimental/control groups in the effectiveness of the skilled performance

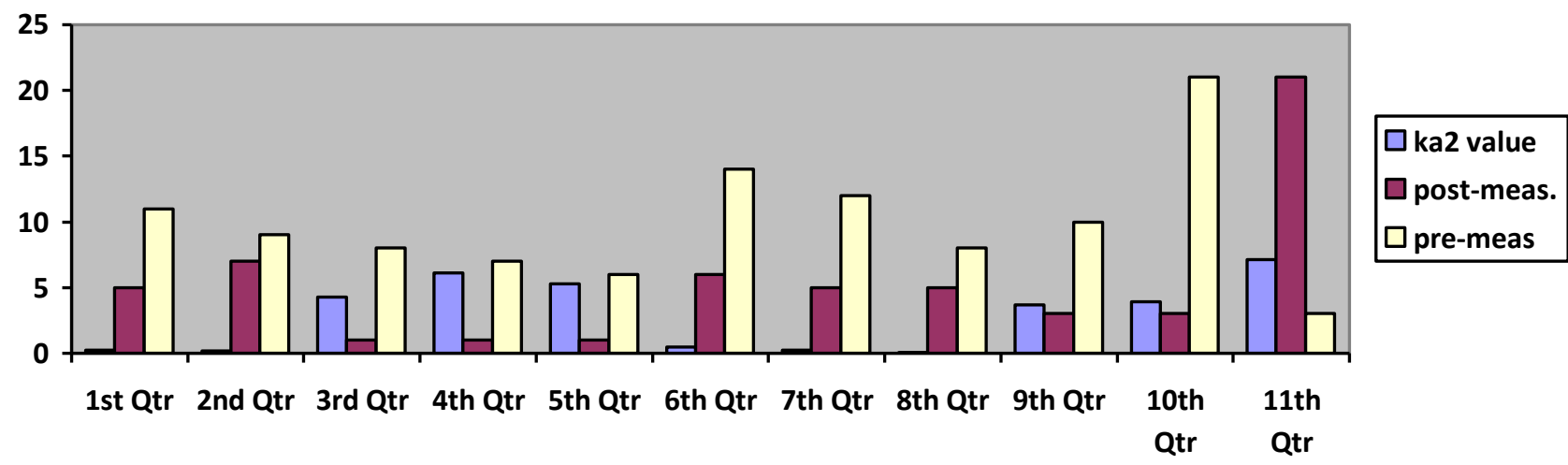

\section{Result Discussion}

Table (4) shows that there are significant statistical differences at the level $(0.05)$ between the pre/post measurements of the experimental group in the strangling skills for the postmeasurement, as the calculated value of ka2 was (3.95) which is higher than the ka2 tabular value at the level (0.05). The researchers attribute this result to the fact that the training, educational program which was applied on the experimental group helped the beginners to get the full benefit of the opportunities to get (yuko, waza, and ippon) of the floor games represented in the pinning, strangling, and breaking skills, which matches the opinion of Mohamed Hamed Shadad (1996), as he believes that Judo player 
shall improve his attacking side through getting used to different attacking situations and how to act in this situations during the games. Table (4) shows that there are significant statistical differences at the level (0.05) between the pre/post measurements of the experimental group in the breaking skills for postmeasurement, as the calculated value of $\mathrm{k} 2$ was (4.74) which is higher than the ka2 tabular value at the level (0.05). The researchers attribute this result to the fact that the training, educational program which was applied on the experimental group helped the beginners to take advantage of the floor games skills specially breaking skills as the player when performing breaking skills and applying it successfully he wins the game because it will be hard for the opponent to get over. The researchers also believe that the breaking skills might be am entrance to the pinning and strangling skills, Fathy Hassan (2001) confirmed that as he indicates that the floor games skills are connected and there are skills in the floor games that pinning, strangling, and breaking can be done in the same time such as (Sankaku jime skill) and that indicates floor games is characterized with a big effectiveness on the games' results.

Table (4) shows that there are significant statistical differences at the level $(0.05)$ between the pre/post measurements of the experimental group in winning for the post-measurement as the calculated ka 23 value was (3.90) which is higher than the ka2 tabular value at the level (0.05). The researchers attribute this result to the fact that the training, educational program which was applied on the experimental group helped the beginners to connect the floor games skills which lead to increase the opportunities to get ippon in the post-measurement and that is what Hassan Fathy (2001)refers to. The researchers also believe that the training, educational program which was applied on the experimental group results in developing attacking through merging the floor games skills and it helped the beginners to focus on implementing the tactical aspects in the different situations of the game, also helped them to use all their potentialities in the attacking side to overcome the opponent. Solima Ali Ibrahim (1996) agrees with that.
Table (5) shows that there are statistical significant differences between the pre/post measurements of the control group for the premeasurement, as the calculated value of $\mathrm{K} 2$ was (7.12) which is higher than the ka2 tabular value at the level (0.05). There are statistical significant differences between the pre/post measurements of the control group in defeat for the post-measurement as the calculated value of $\mathrm{K} 2$ was (3.90) which is higher than the ka2 tabular value at the level (0.05). The researchers attribute that to the fact that the experimental group overcomes the control group I getting ippon through implementing the floor games skills because the training and educational program which was applied on the experimental group make the beginners gain enough selfconfidence and give them the ability to merge floor games skills and getting more scores in (waza and ippon) as the training program which depends on the floor games skills which was applied on the experimental group help the beginner to gain speed and accuracy in implementing the floor games skills, Mohamed Hamed shadad ( 1996) agrees with this.

Table (6) shows that there are statistical significant differences at the level (0.05) between the post-measurements of the experimental /control groups for the postmeasurements of the experimental group as the calculated value of $\mathrm{K} 2$ was (4.27) which is higher than the ka2 tabular value at the level (0.05). There are differences in getting ippon from the strangling skills for the experimental group as the calculated value of K2 was (4.27) which is higher than the ka2 tabular value at the level (0.05) which indicates that there are statistical significant differences at the level (0.05) and there are differences in getting ippon from breaking skills for the experimental group as the calculated value of $\mathrm{K} 2$ was (5.28) which is higher than the ka2 tabular value at the level $(0.05)$ which indicates that there are statistical significant differences at the level (0.05). The researchers attribute that to the fact that the training, educational program which was applied on the experimental group has a positive role in improving the result of the games and the coach shall put this program into account as practicing it make it easier to implement the games tactics which are required to be done during the game. Hassn Fathy Hassan (2001) 
refers to the importance of practicing the skills of the floor games, also, the proposed training, and educational program makes the players gain the ability to attack continually without defending, this shows that the mentioned program have a positive influence in increasing the effectiveness of the skilled performance among beginners beside it makes them gain a new technical tactics in the floor games affects the technical performance during the games. This lead to increasing in floor attacks and the beginners get a huge number of waza and ippon in the post- measurements. This indicates after applying the proposed program the beginners' attacks start having its effectiveness in getting high values. Mohamed Hamed shadad (1996) agrees with that.

\section{Conclusions}

1. There are statistical significant differences at the level (0.05) between the pre/post measurements of the experimental group in getting ippon through the floor games skills (pinning, strangling, and braking) for the postmeasurement.

2. There are statistical significant differences at the level (0.05) between the post-measurements of the experimental/control groups in getting ippon through the floor games skills (pinning, strangling, and braking) for the postmeasurement of the experimental group.

3. The proposed training program leads to develop the skilful shape of Judo through the beginners depending on the floor games skills (pinning, strangling, and braking).

\section{Recommendations}

1. The need to take care of training the beginners on the floor games skills.

2. Make the coaches aware that floor games are important and give 3 possibilities to win the game.

3. Make the coaches aware that floor games are important and how it affects the result of the game.

4. Applying the proposed training, educational program on different stages of age.

\section{References}

1. Hassan Fathy Hassan (2001): "The effectiveness of floor games and its impact on the results of the games in Judo" unpublished Master's thesis, faculty of physical education, Helwan University.

2. Khaled Farid Ezzat (2007): The impact of quality training to develop capacity on some attention aspects and the level of technical performance among Judo beginners, unpublished thesis, faculty of physical education, Mansura University.

3. Soliman Ali Ibrahim (1996): The Judo approach for first year student, unpublished memories

4. Abdel Halim Mohamed Abdel Halim (2011): Modern methods to teac Judo, El wafaa House for printing and puplishing, Alexandria.

5. Mohamed Hamid Shadad (1996): "The physical, skilful, and psychological variables which contributes in the performance level of Judo player" unpublished P.h.D. faculty og physical education, Helwan University.

6. Yasser Yusuf Abdel Rauf (1999): "Establishing test batteries to measure the kinetic ability of Judo players under 17" unpublished P.h.D, faculty of physical education for boys, Helwan University.

7. Geaarge weer (1997): Geaarge weer: transitional control, neilohlenkamp, whcio judo.

8. Stanislaw ,paeel, masl (1996): www.Kodokan.org www.judo.info.com all about judo uplishide by A\&C black puplisheritd gokgo.

9. Kodokan (1991): Judo kodokan , publishing by nono lshobu japan.

10. Kostov, petrov (1996): technices kata podgaovka nemladite dzhudise sti judo training bulgaring.

11. Kodokan (1991): judo kodo kan, prublishing by Nono ishobu - asaka, Japan.

12. Kozmig (1998): my dtudy of judo goher stone lebroly new York. 